\title{
HERMILO BORBA FILHO: UMA POÉTICA DA VIOLÊNCIA
}

\author{
Geralda Medeiros Nóbrega ${ }^{1}$ \\ Elisa Mariana de Medeiros Nóbrega ${ }^{2}$
}

Resumo: Este artigo trabalha a violência institucionalizada em dois contos do escritor pernambucano Hermilo Borba Filho. A personagem Zumba é a vítima que é objeto da repressão policial, com requintes de crueldade. O objetivo é mostrar como se processa este tema, através de uma metodologia que ressalta a memória e os aspectos da cultura popular, sob um enfoque de estudiosos como Bauman, Halbwachs, Maffesoli, Foucault, Bosi e outros.

Palavras-Chave: Violência, Repressão, Cultura popular, Memória.

Abstract: This paper presents the institutionalized violence in two of Hermilo Borba Filho's short stories. Zumba is the character who suffered the brutal and cruel police repression. Our aim is to demonstrate how this particular theme is processed, making use of a methodology concerned with the importance of memory and aspects of popular culture, under the focus of theoreticians such as Bauman, Halbwachs, Maffesoli, Foucault, Bosi, among others.

Keywords: Violence, Repression, Popular culture, Memory.

Como ordenar fatos e acontecimentos nas fendas da literatura, para inserir no espaço do texto aspectos de uma cultura de resistência por onde fluem dimensões simbólicas do mundo, que incitam a pensar? Pretendemos responder a esta pergunta, ao longo deste artigo, em que apresentamos dois contos do escritor pernambucano Hermilo Borba Filho. Este autor dizia

1 Pós-Doutora; Docente do Programa de Pós-Graduação em Literatura e Interculturalidade, da Universidade Estadual da Paraíba (PPGLI/UEPB). Endereço eletrônico: geraldamnobrega@hotmail.com.

2 Docente do Programa de Pós-Graduação em Literatura e Interculturalidade (PPGLI/UEPB) e Professora do Departamento de História, da UEPB, Guarabira. Endereço eletrônico: elisammn@hotmail.com. 
pertencer a uma cultura de resistência e para ele "a dignidade e a liberdade do homem estão em crise e a sua ficção é a única arma de que dispõe para combater a intolerância sob qualquer aspecto em que se apresente" (CIRANO, ALMEIDA, MAURÍCIO, 1981, p. 53).

Eis por que a literatura deste escritor, urdida em tempos fortes de repressão, em plena vigência de ditadura militar, se esbate em um projeto estético que apreende do mundo real aspectos diversificados de forma de violência e os transforma em fatos simbólicos que se traduzem como crítica, como denúncia e como testemunho. Tudo isso afeta o social, o político, o histórico e o cultural, semiotizados. $\mathrm{O}$ autor apreende o modelo autoritário do poder, aparentemente, referente à ditadura de Vargas, década de 30; mas, implicitamente, o que está em foco é a ditadura militar, instalada em 64. É uma literatura de memória, em que o viés testemunhal é representado, no plano ficcional, por fatos e acontecimentos vigentes, em períodos de repressão.

Borba Filho detém-se numa literatura carnavalizada, como um recurso que desvenda o que está encoberto, nas dobras das artimanhas da linguagem, o que motiva o telos da sua poética: combater a repressão, solidarizando-se com os resquícios que ainda deviam instar no âmago das personas que, simbolicamente, estão no cerne das arbitrariedades cometidas pelo poder instituído que evoluía, no universo do real, da tortura até a morte.

Por isto, achamos pertinente o pensamento de Todorov, por se coadunar com o projeto literário de Borba Filho, na significância representativa dos efeitos que o texto suscita:

Sendo o objeto da literatura a própria condição humana, aquele que a lê e a compreende se tornará não um especialista em análise literária, mas um conhecedor dos comportamentos humanos do que uma imersão na obra dos grandes escritores que se dedicam a essa tarefa a milênios (TODOROV, 2009, p. 92-93).

Ora, uma literatura como a de Borba Filho, quando contextualizada, assume uma característica especial, pelo teor de humanidade que se identifica na imanência do texto, ao mesmo tempo pelas semioses disseminadoras do plano de uma ação cidadã de libertação. Lobo (2007) acredita, assim como os aficcionados da literatura, que um caleidoscópio de significâncias em aberto que se constitui como mistério e desafio, torna a literatura um campo inesgotável de representação da vida. Para esta estudiosa: "a literatura é a melhor forma de conhecimento do mundo, porque é, a um tempo, pessoal e universal" (LOBO, 2007, p. 10), o que foi a tônica do projeto literário de Borba Filho. 
No desvendamento do imaginário da resistência, ressaltamos que o ser humano não se contenta em sofrer a história, mas faz história e Borba Filho conseguiu fazer história, fazendo literatura (NÓBREGA, 1996). Os temas desenvolvidos por Borba Filho funcionam como representação de uma realidade prenhe de injustiças, expressas através de uma ficção em que permeia o fantástico e o maravilhoso, que o autor pernambucano denomina de realismo mágico, através do qual representa a denúncia, a crítica e toda sorte de injustiça, presentes no mundo real. É também a sua maneira de desvendar o Nordeste para todos seus leitores:

Agora neste meu Nordeste da Zona da Mata Sul, as pessoas ressuscitam, traem, castigam, enchemse de amores loucos e obsessões, formam uma frenética procissão com os vícios mais cultivados do nosso tempo. Há umas pessoas que levitam, outras que pairam no ar, outras que atravessam terras voando, há peixes que depois de mortos voltam a viver, há bois misteriosos, rãs gigantescas, cavalos metade de carne e metade de flandre, mortos convivendo com vivos. E isto é verdade. Basta prestar atenção (ENTREVISTA, 1974, p. 4).

A técnica de relato de Borba Filho capta do mundo real elementos linguísticos, ideias, temas e assuntos, motivos e tons configuradores da cultura do povo e, através de um processo reinventivo de inovação de linguagem, imerge em dobras significativas do processo criativo, instalado na criatividade de um discurso que se constitui como resistência, naquilo que representa um estilo trabalhado com vigor. E tal qual um cirurgião, quando invade o espaço doente, utiliza partes, amplia, enfoca, distorce, amputa e enovela tudo, para que nada se esquive do seu olhar clínico, que subsidia o seu projeto estético-literário.

E frente ao abandono em que se encontram os excluídos pela classe dominante, no território por onde se infiltram perseguições e torturas, atua o narrador hermiliano como senhor de sua função para, principalmente, transpor os terrenos minados pela ação da ditadura. Trabalharemo com dois contos: "A anunciação", da obra O general está pintando, de 1973 (GEP, daqui para adiante) e "O traidor", da obra Sete dias a cavalo, de 1975 (SDC, daqui para adiante), para demonstrar o compromisso de Borba Filho com a literatura de resistência. Mas deixemos um pouco Borba Filho e recorramos a Bosi (1992, p. 119) para dizer com ele que resistência é um conceito originalmente ético e não estético "e a ideia de resistência, quando conjugada à de narrativa [...], tem sido realizada de duas maneiras que não se excluem necessariamente: a) resistência se dá como tema; b) a resistência se dá como processo inerente à escrita”. E Bosi (1994, p. 365) apresenta a cultura de resistência, entre outras possibilidades, como "democrática (e, no limite, se confunde com a 'desobediência civil'), porque nasceu sob 
o signo da ditadura". Vimos, sob este enfoque, que Borba Filho se enquadra em qualquer aspecto da resistência pois o autor faz uso de temáticas condizentes com a resistência, assim como, através do seu estilo, dá vida ao texto, que representa a crítica, a denúncia e o testemunho, como apoio ao compromisso com sua escritura. A ditadura lidava com o regime de repressão, em que os indivíduos, motivados pela ausência de liberdade, cultivavam o silêncio, num tempo de luto sob as perdas sofridas. O autor deixa antever a reificação das pessoas, ao mesmo tempo que destaca que o luto decorre das arbitrariedades desenvolvidas no mundo real, de que a literatura hermiliana é uma representação. Girard (1990, p. 14) destaca "que a sociedade procura desviar para uma vítima relativamente indiferente, uma vida sacrificável [...] uma violência que talvez golpeasse seus próprios membros, que ela pretende proteger a qualquer custo".

Nos contos hermilianos, a vítima sacrificável é a personagem Zumba, que posteriormente passa a ser chamada de Zumba-Dentão, até se transformar em Zumba-sem-Dente, por conta das sessões de tortura a que era submetido. Logo, o social, submetido ao poder policial, está subordinado à arbitrariedade do poder instituído. Foucault (1999) discute o poder e lembra que o intelectual diz a verdade em nome daqueles que não podem fazê-lo, para reconhecer que as massas falam muito bem a verdade:

\footnotetext{
Mas existe um sistema de poder que barra, proíbe, invalida esse discurso e esse saber. Poder que não se encontra somente nas instâncias superiores da censura, mas que penetra muito profundamente, muito sutilmente em toda a trama da sociedade. Os próprios intelectuais fazem parte desse sistema de poder, a ideia de que são agentes da consciência e do discurso também faz parte desse sistema [...]. O papel do intelectual [...] é antes o de lutar contra as formas de poder, exatamente onde ele é, ao mesmo tempo o objeto e o instrumento: na ordem do saber, da verdade, da consciência, do discurso (FOUCAULT, 1999, p. 71).
}

Borba Filho se insere no centro deste pensamento de Foucault. Nele, a linguagem, personagens, formas de discurso e outros estão a serviço da crítica, da denúncia e de tudo que interfere no humano, como a opressão e os desmandos do poder instituído. Para um escritor para quem o compromisso maior é com o ser humano, Zumba é uma personagem que marca a sua literatura de histórias curtas. Diante de um cartaz que incomodou os poderosos da cidade, diligenciou-se saber quem era o autor. No segundo dia das diligências, o promotor disse que só podem ter sido os bolchevistas. Em seguida, foi decretada a prisão de Zumba, personagem que sobressai, vinculado à dimensão cultural, num espaço representativo do autoritarismo, que reside na omissão e na intolerância que atuam como auxiliar da opressão. Sendo visto 
Pontos de Interrogação, v. 3, n. 1, jan./jul. 2013

Revista do Programa de Pós-Graduação em Crítica Cultural

Universidade do Estado da Bahia (UNEB), Campus II - Alagoinhas - BA

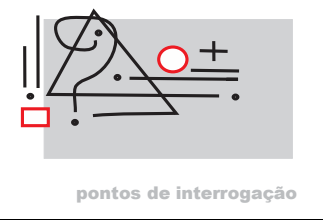

pelos representantes do poder como bolchevista, em qualquer diligência policial era apontado como culpado. "A violência clara, precisa, coercitiva do poder era exercida duramente [...]. Dessa forma [...] é preciso conservar na memória que a pequena violência generalizada caracteriza o ambiente da assepsia social" (MAFFESOLI, 1987, p. 19), o que sempre era aplicado à persona que morava na rua da Ponte com sua mulher, "fazedora de bolo-de-goma, entala-gato, batintope, bolas de cambará, vendidas no tabuleiro para manutenção dos dois" (p. 121). A representação da cultura, na área da alimentação, feita para ser vendida, indica a condição social de Zumba, que sempre pagava por qualquer malfeito impune na cidade. Afinal, "aqueles que detêm os meios de mando e comando, ou dominação e apropriação, muitas vezes podem também instituir o ritmo de atividades [...]” (IANNI, 2002, p. 299), também na aplicação do castigo como sempre acontecia com Zumba, conhecido como Zumba-Dentão, “assim chamado porque nas centenas de prisão porque passara, arrancaram-lhe as unhas e todos os dentes, menos o grandão da frente, jamais nada se provando porque coisa nenhuma existia [...]" (p. 121).

Vemos Borba Filho como um escritor crítico, que através de sua ficção desenvolve uma atuação quase obsessiva no registro de uma análise do mundo real, que expõe como testemunho de acontecimentos abusivos que atingem a cidadania das pessoas. Lendo a obra completa deste autor, incluindo tudo que ele produziu, como sua ficção, teatro, pesquisa, ensaio, outros, reconhecemos que o seu fazer literário é uma fonte de referência para a literatura brasileira e de modo especial para a literatura do Nordeste.

Suas personagens, bem trabalhadas pelo narrador, são imagens de vida, como Zumba. Este, chegando à delegacia, por ordem do delegado,

Levou um tapa-olho do Cabo Luís que viu tudo rodar, tombou, caiu, quando se levantou: se mal pergunto, por que motivo?, levou outro que achanou o pé da goela, procurando ar, nas pontas dos pés como se o ar só estivesse acima dele, foi se aquietando, calado estava calado ficou, então lá vai pergunta, chovia pergunta de todo lado (p. 122).

Zumba sendo objeto de exclusão, não tem como se eximir da perseguição e se torna um alvo fácil para os "maiorais" da cidade. Ele questiona fracamente e sequer chega a queixar-se. Nesta cena da prisão, há o que o narrador classifica de triunvirato, representado pelo juiz, promotor e delegado, embora a grande ironia seja o fato de um poeta, "o vate langoroso" das valsas dançadas no Clube Literário ser encarregado do interrogatório e o fazia recitando Ola- 
vo Bilac. "Se Zumba-Dentão suava ele suava mais ainda, pulava na ponta dos pés, tomava goles de gasosa de bolinha, arrotava fofo, incansável, perquiridor, quer perder o dente?, e o interrogado só sabia dizer que não saí de minha casa” (p. 122).

Isto lembra um alerta de Benjamin (2012) que fala sob o "estado de exceção", trabalhado posteriormente por Agamben (2004). Para Benjamin, centrado na tradição dos oprimidos, o estado de exceção em que vivemos é a regra, o que resulta de uma outra afirmação: "E, assim como o próprio bem cultural não é isento de barbárie, tampouco o é o processo de transmissão em que foi passado adiante" (BENJAMIN, 2012, p. 245). Zumba-Dentão não fez uso daquilo a que tinha direito, já que, segundo Agamben (2004, p. 23), "O problema do estado de exceção apresenta analogias evidentes com o direito de resistência":

No fim da tarde o vate chamou o Cabo Luís e disse arranque, Zumba-Dentão abriu a boca, o Cabo chegou com a torquês, houve um suspense, segurou no pé do dente e puxou, quase nem saiu sangue, quase também que nem doeu, a noite já estava chegando [...] (p. 122).

A violência, uma vez instaurada, dificilmente pode ser controlada. O humano perde a sua importância na coisificação dos seres e Zumbão-Dentão perdendo seu único dente, se transforma em Zumba-sem-Dente. Por isto, chamamos a atenção para o que Maffesoli (1987, p. 15) suscita: "proponho, então, considerar que o termo violência é uma maneira cômoda de reunir tudo o que se refere à luta, ao conflito, ao combate, ou seja, à parte sombria que sempre atormenta o corpo individual ou social", do qual Zumba é representado como vítima. Bauman (2008, p. 58) ressalta:

\footnotetext{
Quer os que estão presos no labirinto tentem ou não encontrar uma saída da opressão - e continuem ou não aguardando sem esperança que a rota de fuga à dissonância possa ser encontrada do lado de dentro das paredes do labirinto -, isso não parece fazer muita diferença no que se refere à sua sorte. Os prêmios pela obediência são entregues de forma torturantemente lenta [...].
}

Isto se adequa à construção da personagem Zumba. $\mathrm{O}$ juiz, conversando à noite com o doutor Bertoldo, ficou sabendo que "o bolchevista estava mesmo de cama com uma disenteria dos diabos, ele lá estivera, o quarteto riu, o doutor se afastou balançando a cabeça" (p. 122). A violência, pois, era uma constante em meio à impunidade institucionalizada e Zumba, uma vítima indefesa.

No texto "O traidor", da obra Sete dias a cavalo (p. 43-53), Zumba, agora Zumba-semDente vivia um período de calmaria, "todo mundo na toca, a ditadura se prolongava e em tempo de ditadura ninguém conspira, cochicha, trama, é esperar que a ditadura passe e chegue 
Pontos de Interrogação, v. 3, n. 1, jan./jul. 2013

Revista do Programa de Pós-Graduação em Crítica Cultural

Universidade do Estado da Bahia (UNEB), Campus II - Alagoinhas - BA

a democracia, aí então voltam a conspiração e o cochicho e a trama". Foi nesta época que Zumba-sem-Dente resolve se candidatar para prefeito, por achar que depois de trinta anos a edilidade precisaria de outras mãos, mãos civis. Candidatou-se contra a vontade de sua mulher que dizia ser ele analfabeto e bolchevista, além de popular, que não tem vez com patente. E Zumba se candidatou, embora tenha sido preso no quarto dia da segunda semana dos seus comícios. Puseram um capuz na sua cabeça e amarraram as mãos dele às costas, conforme informou a sua mulher, no café de Nenê Milhaço, chorando desesperada e pedindo: "me acudam pelo amor de Deus" (p. 47).

Zumba se enquadra nas palavras de Vieira (1998, p. 4) para quem: "a violência e a repressão aparecem normalmente como resposta aos grupos desobedientes, que procuram manifestar suas ideologias e seus interesses, em oposição à legalidade vigente”.

A sociedade reage, até mesmo os notáveis que fabricam o fato como sequestro. Mas a polícia afirmou que ele cometera um furto. A cidade reagiu e formaram-se comitês prólibertação "e apareceram volantes condenando a ditadura da Guarda Nacional" (p. 48). Zumba-sem-Dente era a representação de uma personagem muito popular. Mas era uma figura trágica e não épica. Não reage à tortura. Uma comissão de aproximadamente trezentas pessoas visitou a cadeia e a partir deste acontecimento Zumba-sem-Dente foi posto incomunicável e nem sua mulher podia vê-lo.

Borba Filho, em seus textos, associa os dados culturais aos elementos históricos que funcionam como fatos de uma experiência observável, não propriamente como percepção, mas como um ator que quer lutar pela liberdade, que, na ótica de Albuquerque Júnior (2007), "é aquilo que precisa ser exercido. Creio que nunca pode ser inerente à estrutura das coisas garantir o exercício da liberdade. A garantia da liberdade é a liberdade. É exercê-la" (ALBUQUERQUE JÚNIOR, 2007, p. 126).

O autor vasculha o campo da memória para haurir de suas lembranças a matéria de que necessita para arquitetar o seu texto como crítica, como denúncia e como publicização da opressão, da tortura e do desrespeito à dignidade das pessoas. Zumba-sem-Dente é uma personagem que, entre outras, se adequou àquilo a que Borba Filho se propôs. E mesmo num texto de denúncia como este, o autor aproveita o que é representação da cultura popular para divulgar as manifestações do campo da linguagem em várias modalidades, incluindo também 
os palavrões, os costumes, as visões de mundo, as profissões, tudo que incide nos espaços da cultura, é, enfim, explorado pelo autor.

A memória neste autor sai do âmbito da memória individual, perpassa pela memória coletiva e atinge o itinerário da memória histórica, como detectamos em Halbwachs (2006). Eis por que Borba Filho é detalhista no que concerne a tudo que diz respeito à elaboração de suas personagens, que são condutoras e disseminadoras dos lugares em que vicejam os territórios da cultura e, de modo especial, a cultura popular. A aproximação entre dominantes e dominados, concentrada nos temas trabalhados, remete o discurso para o âmbito da interculturalidade em que os valores cultivados divergem do ponto de vista do poder aquisitivo e do poder de mando.

Quanto à violência policial, nos contos hermilianos, tem o Cabo Luís como mantenedor de todo tipo de arbitrariedade com a aquiescência dos notáveis da cidade. Mesquita Neto (1999) tem uma posição que pode se aplicar ao contexto dos contos hermilianos que tratam da violência:

Durante o regime autoritário (1964-85) o governo federal promoveu claramente ou tolerou a violência policial como um instrumento de controle político, mas especificamente de controle da oposição ao regime autoritário [...], afetando não apenas os oponentes do governo ou do regime político mas também, e principalmente, a população pobre e marginalizada (MESQUITA NETO, 1999, p. 130).

Borba Filho, unindo o projeto estético-literário a um projeto político, desenvolve uma literatura que tem ressonância histórica e, assim, estabelece uma cultura de resistência, compatível com dobras da memória em que as lembranças pedem guarida para se instalarem, e, assim, representam a memória individual que, na ótica de Halbwachs (2006), traça o percurso do coletivo: "A partir daí compreendemos melhor que a representação das coisas evocada pela memória individual não é mais do que uma forma de tomarmos consciência da representação coletiva relacionada às mesmas coisas" (HALBWACHS, 2006, p. 61).

Zumba detinha uma grande liderança em sua cidade, por isto seus amigos e conhecidos emprestaram-lhe irrestrita solidariedade. Ficaram de fora os homens da lei, o padre e o pastor protestante e, na ala militar, o Cabo Luís com o seu destacamento policial, o tenente no cargo de delegado da polícia, e tudo quanto era de capitão e Major da Guarda Nacional, encabeçado pelo prefeito Coronel da Guarda Nacional Atanásio Passos de Albuquerque Coutinho. 
Uma comissão, organizada pelos amigos, visitou a cadeia e, a partir deste acontecimento, Zumba-sem-Dente foi posto incomunicável, conforme já registramos. O narrador nos propõe uma bem aquilatada amostra da cultura popular, referente a nomes de comidas, bebidas, músicas e folguedos.

Tudo se dilui num jogo de linguagem em que se nivela o poder como um duplo. Por um lado, é o poder instituído que aparece como um foco centralizador de decisões, por outro lado atua o poder, representado pela amizade dos amigos. Isto está presente no pensamento de Sodré (1996) que explicita, do ponto de vista social (o que corresponde à junção de dois poderes):

Deste modo, o poder está onde socialmente algo se determina, isto é, onde uma coisa é afirmada como positiva em oposição à outra, negada. Em seu nexo profundo, o poder é organização e gestão dos pontos de contato entre o previsível e o imprevisível, o pleno e o vazio, o símbolo e o polimorfismo existencial (SODRÉ, 1996, p. 62).

Os amigos de Zumba-sem-Dente conseguem mandar um pão para ele e logo na primeira mordida Zumba descobriu um bilhete. "E daí começou a agonia de Zumba-sem-Dente, toda a vida analfabeto gabola, teimando que ninguém precisava saber ler para ser feliz como diziam os que sabiam ler [...]" (p. 52). Enlouquecido, Zumba-sem-Dente cantava, plantava bananeira, brincava de academia, apanhava pedras imaginárias e no quarto dia falava com dificuldade, comia merda, engatinhava e no quinto dia, "chamou o Cabo Luís e pediu-lhe leia isto pelo amor de Deus e me diga o que é" (p. 52).

O Cabo Luís soletrou o bilhete e saiu correndo sem nada dizer a Zumba-sem-Dente que "de nada veio a tomar conhecimento, caindo no tatibitate, no útero para sempre" (p. 52), enquanto dez pessoas foram presas e deslocadas para a capital.

Zumba-sem-Dente, pois, tem uma identidade diluída em meio às instâncias pelas quais passara. Há nele uma pluralidade de identidades, de maneira que "Enquanto estas identidades podem ser experimentadas como uma pluralidade, o Eu é experimentado como uno porque ele é o arcabouço que garante a continuidade sobre a qual a multiplicidade de identidades está inscrita" (GIDDENS, 1989, p. 35).

Então perguntamos: como retirar de alguém o direito de exercer sua cidadania? Preso, depois incomunicável, mesmo depois de morto sofre a violência do poder instituído, através do Cabo Luís: "cagaço da maior, afirmava o Cabo Luís na talagada, na gaitada, no deboche" 